\title{
EDUCAÇÃO FINANCEIRA COMO TEMA TRANSVERSAL NA BASE NACIONAL COMUM CURRICULAR - BNCC
}

\author{
FINANCIAL EDUCATION AS A TRANSVERSAL THEME IN THE \\ COMMON NATIONAL CURRICULUM BASE - BNCC
}

\section{EDUCACIÓN FINANCIERA COMO TEMA TRANSVERSAL EN LA BASE CURRICULAR NACIONAL COMÚN - BNCC}

\author{
Thiago Vieira de Matos ${ }^{1}$ \\ Fabiana Ignacio $^{2}$ \\ Aline Wanderley Camisassa Ditta ${ }^{3}$ \\ Rodrigo Avella Ramirez ${ }^{4}$ \\ Artigo recebido em novembro de 2021 \\ Aprovado em janeiro de 2022
}

\begin{abstract}
RESUMO
Este artigo objetiva investigar como a inserção da Educação Financeira (EF) na educação básica é tratada pela BNCC. Busca-se fundamentação teórica na área de educação e na Legislação Brasileira para que se explorem os conceitos trazidos pela BNCC. A análise da inserção da EF na BNCC mostrase importante e necessária considerando o relevante impacto do conhecimento de Educação Financeira para a formação do jovem, para a construção do seu projeto de vida e sua inserção no mundo do trabalho de forma consciente, crítica e cidadã. Dessa forma, para alcançar o objetivo proposto, utilizase a análise documental como eixo metodológico. Os resultados indicam que, mesmo a normativa trazendo a Educação Financeira como um tema transversal e de relevância em várias áreas de estudo, ainda não está claro como o assunto pode ser implantado e desenvolvido pelas instituições de ensino.
\end{abstract}

Palavras-chave: Currículo. Transversalidade. Educação Financeira. BNCC.

\begin{abstract}
This article aims to investigate how the insertion of Financial Education-FE in basic education is treated by the BNCC. Theoretical foundation is sought in the area of education and in Brazilian legislation so that the concepts brought by BNCC can be explored. The analysis of FE's insertion in the BNCC is important and necessary considering the relevant impact of knowledge of Financial

\footnotetext{
${ }^{1}$ Mestrando em Educação Profissional do Centro Estadual de Educação Tecnológica Paula Souza. E-mail: thiago.matos@cpspos.sp.gov.br.

${ }^{2}$ Mestranda em Educação Profissional do Centro Estadual de Educação Tecnológica Paula Souza. E-mail: fabiana.ignacio@cpspos.sp.gov.br.

${ }^{3}$ Mestranda em Educação Profissional do Centro Estadual de Educação Tecnológica Paula Souza. E-mail: aline.ditta@cpspos.sp.gov.br.

${ }^{4}$ Professor do programa de mestrado em Educação Profissional do Centro Estadual de Educação Tecnológica Paula Souza. E-mail: roram100@ hotmail.com.
} 
Education for the formation of young people, for the construction of their life project and their insertion in the world of work in a conscious, critical and citizen. Thus, to achieve the objective of this text, document analysis is used as a methodological axis. The results indicate that, even though the regulations bring Financial Education as a cross-cutting theme of relevance in several areas of study, it is still not clear how the subject can be implemented and developed by educational institutions.

Keywords: Curriculum. Transversality. Financial Education. BNCC.

\section{RESUMEN}

Este artículo tiene como objetivo investigar cómo el BNCC aborda el tema Educación Financiera Educación Física para los planes de estudio escolares y cuáles son las pautas para su implementación. Se busca fundamento teórico en Perrenoud, Sacristán, Alessandrini y en la Legislación brasileña para que se puedan explorar los conceptos traídos por BNCC. Así, para lograr el objetivo de este texto, el análisis documental se utiliza como eje metodológico. Los resultados indican que, si bien la normativa lleva a la Educación Financiera como un tema transversal de relevancia en varias áreas de estudio, aún no está claro cómo el tema puede ser implementado y desarrollado por las instituciones educativas.

Palabras clave: Currículum. Transversalidad. Educación Financiera. BNCC.

\section{INTRODUÇÃO}

A BNCC - Base Nacional Comum Curricular é o documento oficial do Estado Brasileiro que define as aprendizagens essenciais que devem ser desenvolvidas junto aos alunos em todas as modalidades e etapas do percurso educacional escolar básico. A normativa é uma sinergia de forças sociais impulsionada pela Constituição Federal de 1988, pela LDB 9.394/1996 e pelas Diretrizes Curriculares Nacionais da Educação Básica - DCN (Parecer CNE/CEB $\mathrm{n}^{\circ} 4$ de 13 de julho de 2010.

O documento orienta a construção dos currículos escolares nos sistemas Federal, Estadual e Municipal e alinha as políticas e ações educacionais voltadas para a formação do corpo docente das instituições de ensino, a avaliação dos processos e métodos de aprendizagem, aos critérios e definições dos conteúdos, além de orientar a adequada infraestrutura para que sejam viabilizadas as ofertas educacionais. A BNCC tem uma vocação normativa, uma vez que se caracteriza como "um conjunto orgânico e progressivo de aprendizagens essenciais que todos os alunos devem desenvolver ao longo das etapas e modalidades da Educação Básica” (BNCC, 2018.p.7).

Sua característica essencial é ampla e aberta na busca de contemplar as mais diferentes realidades pedagógicas e sociais em todo o território nacional. Dessa forma, a BNCC está voltada para a garantia da construção de um repertório comum de aprendizagem em que se garantam os princípios educacionais defendidos na Constituição de 1988, no PNE - Plano Nacional da Educação e nas DCN e está voltada "para a formação humana integral e a construção de uma sociedade justa, democrática e inclusiva", como está descrito em seu texto base.

A Base Nacional Comum Curricular respeita a autonomia das unidades federativas para que os sistemas e redes de ensino possam construir currículos e 
as escolas elaborem propostas pedagógicas considerando as necessidades, possibilidades e interesses dos educandos. A igualdade, a diversidade e a equidade são conceitos que devem estar presentes na implementação das diretrizes da BNCC, além das identidades linguísticas, étnicas e culturais de cada uma das localidades onde se desenvolve o processo educacional.

O que se pretende, então, com a discussão aqui proposta, é investigar de que forma a BNCC propõe a inclusão do tema Educação Financeira - EF para os currículos escolares e qual o aparato que poderá e/ou deverá ser desenvolvido pelas instituições de ensino para a concretização dessa proposta. Surge então a necessidade de um olhar direcionado para os documentos norteadores da EF na educação escolar nacional e, nesse caso, especialmente a BNCC para verificar como a Educação Financeira poderá ser inserida na proposta educacional brasileira.

\section{REFERENCIAL TEÓRICO}

O referencial teórico apresentado aborda os principais conceitos presentes nos documentos analisados, como competências, transversalidade e currículo, explora as referências de Educação Financeira na BNCC e, em seguida, a indicação dos principais marcos históricos da Educação Financeira no Brasil.

\subsection{Principais conceitos}

Resultado de amplos debates com a participação de diversos atores da educação brasileira, a BNCC visa garantir um conjunto de aprendizagens necessárias para preparar os estudantes para o futuro pessoal e profissional. Essas aprendizagens estão organizadas em competências gerais que serão fundamentais para a concretização dos projetos de vida e continuidade dos estudos dos alunos.

Competência, segundo Alesssandri (2002), refere-se à capacidade de compreender e avaliar uma situação determinada para estabelecer e adotar a melhor solução. Desta forma, a BNCC propõe o desenvolvimento de habilidades para a construção das competências necessárias para o desenvolvimento integral do estudante nos diversos itinerários formativos.

Entender o conceito e significado de competência se justifica pela proposição da norma, que categoriza as dez competências gerais que um sujeito deverá ser capaz de desenvolver ao percorrer o ensino escolar regular e,

valorizar a diversidade de saberes e vivências culturais e apropriar-se de conhecimentos e experiências que lhe possibilitem entender as relações próprias do mundo do trabalho e fazer escolhas alinhadas ao exercício da cidadania e ao seu projeto de vida, com liberdade, autonomia, consciência crítica e responsabilidade (BNCC, 2018. p.9). 
A primeira menção que se pode observar em relação a Educação Financeira é estabelecida na sexta competência que alude ao mundo do trabalho e à capacidade de o sujeito fazer escolhas relativas à vida social, que vão perpas sar, inclusive, pela capacidade de lidar com os rendimentos pecuniários oriundos da atividade profissional. Como será ampliado mais adiante, a BNCC trata a Educação Financeira como um tema transversal, ou seja, que pode ser abordado em diversas áreas do conhecimento, seja através da aplicação prática ou pela abordagem conceitual e histórica da temática. De uma maneira ou de outra, figura na normativa e tem nela certo destaque a importância de a pessoa desenvolver a capacidade de lidar com recursos financeiros como parte do seu desenvolvimento e integração social e sublinhar os pontos e as justificativas que abordam a Educação Financeira dentro da BNCC será a espinha dorsal desse artigo.

Para que se possa direcionar os conceitos aqui tratados, a BNCC define como competência.

O que os alunos devem "saber" (considerando a constituição de conhecimentos, habilidades, atitudes e valores) e, sobretudo, do que devem "saber fazer" (considerando a mobilização desses conhecimentos, habilidades, atitudes e valores para resolver demandas complexas da vida cotidiana, do pleno exercício da cidadania e do mundo do trabalho) (BNCC, 2018. p.13).

Outro conceito importante e indispensável para o desenvolvimento do presente estudo é transversalidade, uma vez que na BNCC está indicado que os sistemas e redes de ensino, dentro de suas condições de autonomia e competências, incorporem de forma transversal e integradora, em seus currículos e propostas pedagógicas, temas como educação para o consumo, educação financeira, entre outros.

A transversalidade é a inclusão de temas que refletem questões relevantes para o enfrentamento dos desafios cotidianos nas áreas de conhecimento já presentes na proposta pedagógica escolar. Temas transversais compõe-se por temáticas relevantes para a formação integral e construção da cidadania do aluno, para além dos conteúdos estabelecidos para as disciplinas curriculares.

Discussões sobre competências e transversalidade podem ser discutidas a partir de uma dimensão curricular pois, em termos gerais, como afirma Sacristán (2013), um currículo trata de tudo aquilo que será apreendido por um estudante em sua trilha educacional escolar, é organizado e selecionado para transmitir e socializar os valores de cada sociedade, com o fim de perpetuar sua existên cia e mediar seu repertório cultural. Nesse sentido, e a partir desse esclarecimento oferecido pelo autor, a BNCC figura como um dos instrumentos pelos quais a sociedade brasileira demarca suas fronteiras de cultura e determina os comportamentos sociais que deverão ser seguidos por seus cidadãos, bem como as possíveis formatações para sua implementação.

\subsection{Marcos históricos da Educação Financeira no Brasil}


A Educação Financeira é um tema atual e presente em debates de diversas áreas: foco central em estudos de psicologia econômica; conteúdo de destaque em iniciativas educacionais de instituições financeiras; fundamenta reflexões sobre direitos e deveres do consumidor; e desponta como tema transversal na Base Nacional Comum Curricular - BNCC. A necessidade de refletir sobre como contribuir para que os indivíduos possam ser inseridos de forma crítica e consciente na sociedade de consumo em que vivemos, torna imprescindível o desenvolvimento de conhecimentos e ações em Educação Financeira.

$\mathrm{Na}$ literatura consultada, deparamo-nos com diversos conceitos de Educação Financeira, praticamente todos derivados do conceito apresentado pela Organização para Cooperação e Desenvolvimento Econômico - OCDE.

Educação Financeira é o processo mediante o qual os indivíduos e as sociedades melhoram a sua compreensão em relação aos conceitos e produtos financeiros, de maneira que, com informação, formação e orientação, possam desenvolver os valores e as competências necessários para se tornarem mais conscientes das oportunidades e riscos neles envolvidos e, então, poderem fazer escolhas informadas, saber onde procurar ajuda e adotar outras ações que melhorem o seu bem-estar. Assim, podem contribuir de modo mais consistente para a formação de indivíduos e sociedades responsáveis, comprometidos com o futuro (OCDE,2005).

Para a compreensão do estágio atual da Educação Financeira como tema transversal na BNCC, faz-se necessário um olhar sobre os marcos históricos do tema nas diretrizes educacionais, políticas e econômicas brasileiras. Para tanto, apresentar-se-á a seguir os principais movimentos das políticas governamentais para a inclusão da Educação Financeira como tema central nos discursos da sociedade nacional.

A Educação Financeira no Brasil passa a fazer parte dos debates governamentais em 2006, quando foi constituído o Comitê de Regulação e Fiscalização dos Mercados Financeiros, de Capitais, de Seguros, de Previdência e de Capitalização - Coremec, por meio da publicação do Decreto $\mathrm{N}^{\circ} 5.685$, de 25 de janeiro de 2006. O decreto institui o Coremec com a finalidade de promover a coordenação e o aprimoramento da atuação das entidades da administração pública federal que regulam e fiscalizam as atividades relacionadas à captação pública da poupança popular.

Conforme previsto no Art. $2^{\circ}, \S 7^{\circ}$ do Decreto $5.685 / 2006$, dentre uma de suas atribuições, compete ao Coremec a criação de Grupos de Trabalho - GT destinados ao exame de assuntos específicos, integrados por representantes das entidades e órgãos que compõem o Coremec, bem como especialistas convidados para contribuir com um GT específico. Desta forma, em 31 de maio de 2007 o Coremec, com a publicação da Deliberação $\mathrm{N}^{\circ} 3$, torna pública sua decisão de constituir o Grupo de Trabalho - GT com o propósito de propor a Estratégia Nacional de Educação Financeira, sob a coordenação da CVM - Comissão de Valores Mobiliários.

Dentre as atribuições do GT, definidas no Art. $5^{\circ}$ da Deliberação $\mathrm{N}^{\circ} 3$, destacam-se: deliberar sobre a estrutura da estratégia; sugerir áreas, públicos e temas a serem priorizados; estimar recursos necessários à execução das ações propostas. Cabe ressaltar que, dentre os objetivos a serem priorizados, constam o 
crescimento do mercado, a inclusão financeira, a proteção do investidor e o desenvolvimento social. A ampliação do mercado financeiro e a promoção da inclusão financeira, certamente favorecida pelo acesso ao crédito, remetem a uma visão neoliberal, onde a lógica do capital é estendida a todas as relações na sociedade pós-moderna.

Como áreas a serem priorizadas na Estratégia Nacional de Educação Financeira a deliberação indica: "desenvolvimento de habilidades em finanças pessoais, estímulo à poupança, relacionamento com crédito, microcrédito, financiamento à habitação, proteção de investidores, inclusão no sistema financeiro, previdência e preparação para a aposentadoria, seguros, entre outros". Ao favorecer o aprofundamento dos conhecimentos da população brasileira sobre essas áreas, a proposta da Estratégia Nacional de Educação Financeira contribui para a formação de indivíduos e sociedades responsáveis, comprometidos com o futuro, de acordo com a definição de Educação Financeira proposta pela OCDE.

Como resultado das discussões promovidas pelo GT constituído pelo Coremec, tem-se a publicação do Decreto $N^{\circ} 7.397$, de 22 de dezembro de 2010, que formalmente institui a Estratégia Nacional de Educação Financeira - ENEF que tem sua finalidade apontada no Art. $1^{\circ}$.

\begin{abstract}
Art. $1^{\circ}$ Fica instituída a Estratégia Nacional de Educação Financeira - ENEF com a finalidade de promover a educação financeira e previdenciária e contribuir para o fortalecimento da cidadania, a eficiência e solidez do sistema financeiro nacional e a tomada de decisões conscientes por parte dos consumidores.
\end{abstract}

A partir da análise da finalidade estabelecida para a ENEF, pode-se constatar que há duas vertentes de foco: a primeira que diz respeito ao indivíduo, quando prevê o fortalecimento da cidadania e a formação de consumidores capazes de adotarem decisões conscientes com relação ao uso do dinheiro. A segunda vertente diz respeito às instituições financeiras, quando aponta para a necessidade e possibilidade de fortalecimento da eficiência e solidez do próprio sistema financeiro nacional. Britto $(2013$, p.174) aponta "o risco de que o "credo econômico-financeiro' esteja a compor, de forma dominante, as propostas de Educação Financeira", por meio da metáfora de lobos cuidando das ovelhas ao se referir à participação intensa das instituições financeiras nas definições da Estratégia Nacional de Educação Financeira - ENEF.

Ainda no Decreto No 7.397, de 22 de dezembro de 2010 consta a criação do Comitê Nacional de Educação Financeira - CONEF, composto por representantes de ministérios - do Trabalho e Previdência Social; da Justiça; da Fazenda; da Educação - de órgãos reguladores - Comissão de Valores Mobiliários; Superintendência Nacional de Previdência Complementar; Superintendência de Seguros Privados - e de instituições financeiras - Banco Central do Brasil - além de representantes da sociedade civil. Ao CONEF cabe a responsabilidade de promover a ENEF por meio de programas e ações de Educação Financeira, estabelecendo metas para o planejamento, financiamento, execução, avaliação e constante revisão da Estratégia Nacional de Educação Financeira (Decreto 7.397 - Art $4^{\circ}$ ). Para assessorar o CONEF, o mesmo decreto prevê a criação do Grupo de Apoio Pedagógico, responsável pela elaboração de planos para programas e ações de Educação Financeira a serem implementados em âmbito nacional. 
Em 2011, o CONEF foi responsável pela criação da Associação de Educação Financeira do Brasil - AEF-Brasil, uma OSCIP - Organização da Sociedade Civil de Interesse Público - com o propósito de implementar ações e programas da Estratégia Nacional de Educação Financeira. A AEF-Brasil, mantida por relevantes instituições do mercado financeiro - Anbima ${ }^{5}$, $\mathrm{CNseg}^{6}$, BMF\&Bovespa ${ }^{7}$ e Febraban ${ }^{8}$ - tem como missão contribuir para o fortalecimento da cidadania, promovendo e apoiando ações que contribuam para que os indivíduos possam tomar decisões autônomas e conscientes; coincidente com o propósito da própria ENEF.

Promulgado em 9 de junho de 2020, o Decreto $\mathrm{N}^{\mathrm{o}} 10.393$ institui a nova Estratégia Nacional de Educação Financeira - ENEF, com a finalidade de promover a educação financeira, securitária, previdenciária e fiscal no país e a criação do Fórum Brasileiro de Educação Financeira - FBEF, revogando o disposto no Decreto $\mathrm{N}^{\circ} 7.397 / 2010$. A nova diretriz governamental para a Educação Financeira diferencia-se da anterior em alguns aspectos: (i) não inclui representantes da sociedade civil em seu corpo colegiado; (ii) não indica o foco na formação do indivíduo como cidadão, capaz de adotar atitudes conscientes com relação ao consumo, privilegiando apenas a finalidade de promover a educação financeira, securitária e fiscal no país; (iii) mantém apenas o Ministério da Educação na composição do FBEF, excluindo os demais ministérios que faziam parte do CONEF; e (iv) prevê a interlocução do FBEF com os órgãos ou as entidades públicas e as instituições privadas para estimular a realização de ações de educação financeira, securitária, previdenciária e fiscal para a sociedade brasileira.

Este decreto causa impacto no cenário da Educação Financeira no Brasil, com alguns importantes desdobramentos:

a) O Banco Central do Brasil anunciou em maio de 2021 o lançamento da expansão do programa Aprender Valor, que tem por objetivo apoiar as Secretarias Estaduais e Municipais Educação para a implementação do tema Educação Financeira e Educação para o Consumo nas escolas públicas de Ensino Fundamental. Este programa está em consonância com o previsto na BNCC para que os temas Educação Financeira e Educação para o Consumo sejam inseridos de forma transversal nos currículos da educação básica;

b) A AEF-Brasil, encerrou suas atividades em junho de 2021, uma vez que seus mantenedores deixaram de fazer parte do FBEF, responsável pela definição da ENEF. O legado deixado pela atuação da AEF-Brasil na capacitação de professores da rede pública de educação básica é significativo e faz parte de importante marco histórico da Educação Financeira no Brasil;

c) O Ministério da Educação e a CVM delineiam as premissas e assinam, em agosto de 2021, um acordo para a implementação de um programa de formação de professores para o desenvolvimento de atividades de Educação Financeira para os

\footnotetext{
${ }^{5}$ Associação Brasileira das Entidades dos Mercados Financeiro e de Capitais - Anbima.

${ }^{6}$ Confederação Nacional das Empresas de Seguros Gerais, Previdência Privada e Vida, Saúde Suplementar e Capitalização - Cnseg.

${ }^{7}$ Bolsa de Mercadorias \& Futuros - BM\&F; Bolsa de Valores de São Paulo - Bovespa. Em março de 2017, com a fusão entre a BM\&F Bovespa e a Cetip - Central de Custódia e Liquidação de Títulos, a Bolsa de Valores do Brasil passou a ser denominada B3.

${ }^{8}$ Federação Brasileira de Bancos - Febraban.
} 
alunos da rede pública e privada de ensino, com a meta de capacitar 500 mil alunos em três anos.

Promulgada pelo Ministério da Educação em 2017, a Base Nacional Comum Curricular, a deveria ser implementada em todas as escolas brasileiras até o final de 2021 - prazo prorrogado para 2022 em função da pandemia, aponta para a inclusão do tema Educação Financeira como tema transversal.

Por fim, cabe aos sistemas e redes de ensino, assim como às escolas, em suas respectivas esferas de autonomia e competência, incorporar aos currículos e às propostas pedagógicas a abordagem de temas contemporâneos que afetam a vida humana em escala local, regional e global, preferencialmente de forma transversal e integradora. Entre esses temas, destacam-se: [...] educação para o consumo, educação financeira e fiscal. [...] (BNCC, p.18).

A partir da homologação da BNCC, as redes de ensino pública e particular têm como desafio a construção dos currículos, incluindo as aprendizagens e competências previstas na BNCC de forma a transformar as diretrizes em planos de ação na prática educacional.

\section{MÉTODO}

O percurso metodológico que se adotou para o desenvolvimento desse trabalho foi a partir da análise documental do texto base da BNCC - Base Nacional Comum Curricular e, a partir desse estudo, o levantamento do tema Educação Financeira e a forma como esse é explorado, desenvolvido e proposto dentro da normativa, levando em consideração os princípios propostos pela norma na constituição e busca por uma sociedade em que seus sujeitos sejam capazes de viver e interagir, bem como conduzir suas vidas frente às transformações sociais que se tornam dia a dia mais presentes pelo avanço das tecnologias e massificação dos meios de comunicação.

Para Lüdke e André (2020), a análise documental é uma técnica valiosa para estudo de dados qualitativos, possibilitando analisar em profundidade um tema específico. Para tanto, análise o presente artigo tem embasamento a análise de documentos legais como: leis, decretos, diretrizes e outros documentos que compõem o arcabouço legal da educação básica brasileira. Esses documentos constituem uma fonte rica e aprofundada sobre o tema proposto, possibilitando a identificação de evidências sobre a inserção da Educação Financeira na Base Nacional Comum Curricular - BNCC, considerando o contexto legal que fundamenta o surgimento do tema nas discussões acerca da educação na sociedade brasileira.

A partir da análise da documentação selecionada, os autores propõem pontos relevantes a serem considerados para a efetiva inclusão da Educação Financeira como tema transversal na educação básica. 


\section{RESULTADOS E DISCUSSÃO}

Iniciam-se os resultados e discussão pela educação financeira na legislação da educação brasileira.

\subsection{A Educação Financeira na legislação da educação brasileira}

A legislação brasileira apresenta, desde a sua constituição como República, diretrizes específicas para a organização da Educação Básica que, a partir da Lei de Diretrizes e Bases da Educação - LDB No 9.394/ 1996 (Brasil, 1996) passa a ser estruturada por etapas e modalidades de ensino, incluindo a Educação Infantil, o Ensino Fundamental. A LDB 9.394/1996 apresenta a educação como um fenômeno que abrange processos formativos tanto no âmbito familiar, quanto nos âmbitos social, do trabalho, de movimentos sociais, de instituições de ensino e pesquisa, além do escolar propriamente dito, conceito esse que permeia as reflexões de Sacristán (2002).

A educação consiste, antes de tudo, em tornar disponível para o sujeito o mundo não abrangido pela experiência que ele, entregue a seus próprios meios, não poderia obter (Sacristán, 2002, p. 39).

Explicitamente não há menção, no corpo da Lei de Diretrizes e Bases da Educação - LDB No 9.394/1996, à Educação Financeira ou assuntos correlatos; trata-se de uma peça legal que estabelece as diretrizes gerais para a educação básica no país. A referida legislação, no Art. $1^{\circ}$ - $\$ 2^{\circ}$ indica que a educação escolar deverá vincular ao mundo do trabalho e à prática social. Cabe então, nesse contexto, refletir sobre a necessidade da Educação Financeira como forma de preparar o sujeito para o exercício da cidadania e para a inserção no mundo do trabalho, lidando com as questões financeiras de forma consciente, saudável e sustentável, mesmo não havendo citação direta ao tema.

Em 4 de abril de 2013 é sancionada a Lei $n^{\circ} 12.796$, que altera a Lei $n^{\circ}$ 9.394/1996, que dispõe sobra as diretrizes e bases da educação nacional, estendendo a educação básica obrigatória, estabelecendo diretrizes sobre a formação dos profissionais de educação, bem como outras providencias relacionadas ao tema. De uma forma geral, não há alteração significativa no corpo da lei, cabendo destaque à importância dada à questão da formação inicial e continuada para os profissionais da educação; questão essa de suma importância para a viabilização da inclusão do tema Educação Financeira, proposta na BNCC - Base Nacional Comum Curricular que em breve estaria em processo de elaboração.

A BNCC é formalmente inserida no arcabouço legal da educação nacional quando sancionada a Lei 13.415, de 16 de fevereiro de 2017, que modificou artigos da LDB/1996 para a inclusão da base:

Art. 36: A Base Nacional Comum Curricular definirá direitos e objetivos de aprendizagem do ensino médio, conforme diretrizes do Conselho Nacional de Educação, nas seguintes áreas de conhecimento:

I - Linguagens e suas tecnologias

II - Matemática e suas tecnologias 
III - Ciências da natureza e suas tecnologias

IV - Ciências humanas e sociais aplicadas.

O caput do art. 26, da LDB/1996 estabelece que os currículos de cada uma das etapas da educação básica sejam elaborados em consonância com o disposto na BNCC, sendo complementados por uma parte diversificada, respeitando-se as características regionais e locais da sociedade, da cultura, da economia e dos próprios sujeitos focos do processo educacional.

$\S 1^{\circ}$ A parte diversificada dos currículos de que trata o caput do art. 26, definida em cada sistema de ensino, deverá estar harmonizada à Base Nacional Comum Curricular e ser articulada a partir do contexto histórico, econômico, social, ambiental e cultural.

A partir deste levantamento de informações sobre os aspectos legais que estabelecem as diretrizes para a educação básica, a pesquisa documental tem como foco a análise do documento oficial BNCC - Base Nacional Comum Curricular, homologado pelo Ministério da Educação, que estabelece as orientações especialmente para a três etapas do ensino básico: Educação Infantil, Ensino Fundamental e Ensino Médio. Adota-se como objeto de estudo as diretrizes da BNCC para o Ensino Médio, etapa final da Educação Básica e locus da educação técnica profissional.

Art. 36: O currículo do Ensino Médio será composto pela Base Nacional Comum Curricular e por itinerários formativos, que deverão ser organizados por meio da oferta de diferentes arranjos curriculares, conforme relevância para o contexto local e a possibilidade dos sistemas de ensino, a saber:

I - Linguagens e suas tecnologias;

II - Matemática e suas tecnologias;

III - Ciências da natureza e suas tecnologias;

IV - Ciências humanas e sociais aplicadas;

V - Formação técnica e profissional.

\subsection{A Educação Financeira na BNCC}

A Educação Financeira, considerada pela OCDE como o processo em que "os indivíduos e sociedades melhoram a sua compreensão em relação aos conceitos e produtos financeiros", é uma das temáticas da atualidade sugerida para compor a Base Nacional Comum Curricular. (MINISTÉRIO DA EDUCAÇÃ̃, 2016).

Ao analisar detalhadamente o documento oficial da BNCC publicado em 2018, quando da inclusão da parte relativa ao Ensino Médio, identificou-se a ocorrência da expressão "Educação Financeira" em 6 (seis) diferentes pontos. O primeiro deles encontra-se na parte introdutória da BNCC, referindo-se à Educação Financeira como um dos temas contemporâneos, que devem permear o currículo de forma transversal e integradora.

Por fim, cabe aos sistemas e redes de ensino, assim como às escolas, em suas respectivas esferas de autonomia e competência, incorporar aos currículos e às propostas pedagógicas a abordagem de temas contemporâneos que afetam a vida humana em escala local, regional e global, preferencialmente de 
forma transversal e integradora. Entre esses temas, destacam-se: [...] educação para o consumo, educação financeira e fiscal. [...] (BNCC, p.18).

Na parte referente à área de Matemática, a BNCC ressalta a importância do conhecimento matemático para todos os alunos da educação básica, considerando sua importante aplicação na sociedade contemporânea e sua contribuição para a formação de cidadãos críticos e socialmente responsáveis.

O conceito Educação Financeira está inserido em quatro habilidades destacadas para o Ensino Fundamental que, segundo a BNCC, deve ter o "compromisso com o desenvolvimento do letramento matemático". (BNCC p. 266) essas habilidades relacionam-se a competências de raciocínio, representação, comunicação e argumentação matemáticas, favorecendo a tomada de decisões e resoluções de problemas encontrados no cotidiano. Essas competências e habilidades são fundamentais para a formação de cidadãos críticos, conscientes e socialmente responsáveis.

No Quadro 1, listam-se as habilidades indicadas na BNCC para os diferentes anos do Ensino Fundamental que contém a citação específica de Educação Financeira.

Quadro 1 - Educação Financeira nas habilidades da BNCC para o Ensino Fundamental

\begin{tabular}{|c|c|c|}
\hline Ano & Habilidade & Descrição \\
\hline $5^{\text {o Ano }}$ & EF05MA06 & $\begin{array}{r}\text { Associar as representações } 10 \%, 25 \%, 50 \%, 75 \% \text { e 100\% } \\
\text { respectivamente à décima parte, quarta parte, metade, três quartos e um } \\
\text { inteiro, para calcular porcentagens, utilizando estratégias pessoais, } \\
\text { cálculo mental e calculador, em contextos de educação financeira, } \\
\text { entre outros. }\end{array}$ \\
\hline $6^{\text {o Ano }}$ & EF06MA13 & $\begin{array}{r}\text { Resolver e elaborar problemas que envolvam porcentagens, com base } \\
\text { na ideia de proporcionalidade, sem fazer uso da "regra de três", } \\
\text { utilizando estratégias pessoais, cálculo mental e calculadora, em } \\
\text { contextos de educação financeira, entre outros. }\end{array}$ \\
\hline $7^{\text {o Ano }}$ & EF07MA02 & $\begin{array}{r}\text { Resolver e elaborar problemas que envolvam porcentagens, como os } \\
\text { que lidam com acréscimos e decréscimos simples, utilizando } \\
\text { estratégias pessoais, cálculo mental e calculadora, no contexto de } \\
\text { educação financeira, entre outros. }\end{array}$ \\
\hline EF09MA05 & $\begin{array}{r}\text { Resolver e elaborar problemas que envolvam porcentagens, com a ideia } \\
\text { de aplicação de percentuais sucessivos e a determinação das taxas } \\
\text { percentuais, preferencialmente com o uso de tecnologias digitais, no } \\
\text { contexto da educação financeira. }\end{array}$ \\
\hline
\end{tabular}

Fonte: Elaborado pelos autores

A análise do detalhamento de cada uma dessas habilidades indica o foco em questões relacionadas a percentuais, restringindo enormemente o campo de conhecimento sobre Educação Financeira. Baseando-se no conceito adotado pela 
OCDE, a Educação Financeira inclui o conhecimento e compreensão de produtos financeiros, a análise de possibilidades de investimentos e respectivos riscos, bem como a adoção de decisões financeiras que garantam o bem-estar no presente e a tranquilidade no futuro, atuando como indivíduos crítica e socialmente responsáveis. Ao estabelecer como foco apenas a questão de entendimento de percentuais, essa abordagem mais ampla proposta pela OCDE não é contemplada pelas habilidades indicadas.

A sexta referência à Educação está presente na introdução da parte 5.4., referente à área de Ciências Humanas e Sociais Aplicadas.

Há hoje mais espaço para o empreendedorismo individual, em todas as classes sociais, e cresce a importância da educação financeira e da compreensão do sistema monetário contemporâneo nacional e mundial, imprescindíveis para uma inserção crítica e consciente no mundo atual (BNCC, p. 568).

A BNCC aponta para as transformações da sociedade, principalmente em função do uso de novas tecnologias, que determinam transformações na participação dos trabalhadores nos processos produtivos, nas relações de trabalho e nas alterações dos índices relativos à ocupação, emprego e desemprego. Essas transformações apontam para a necessidade da compreensão dos impactos das inovações tecnológicas nas relações de trabalho e de consumo, principalmente em função da transformação da sociedade, segundo Rifikin (1995), em sociedade de consumo do século XXI.

Por ser tratada como tema transversal dentro da BNCC, a Educação Financeira aparece em mais de um campo de estudos, apresentando abordagens diferenciadas em cada uma delas. O que se apresenta a partir desse ponto é como a temática é apresentada, discutida e proposta em cada um dos campos de estudos da normativa. A relevância do estudo da Educação Financeira está sustentada na norma pela necessidade da observância e atuação dos cidadãos no mundo contemporâneo, que exige das pessoas novas habilidades e competências ao afirmar que

\begin{abstract}
atualmente, as transformações na sociedade são grandes, especialmente em razão do uso de novas tecnologias. Observamos transformações nas formas de participação dos trabalhadores nos diversos setores da produção, a diversificação das relações de trabalho, a oscilação nas taxas de ocupação, emprego e desemprego, o uso do trabalho intermitente a desconcentração dos locais de trabalho, e o aumento global da riqueza, suas diferentes formas de concentração e distribuição, e seus efeitos sobre as desigualdades sociais. Há hoje mais espaço para o empreendedorismo individual, em todas as classes sociais, e cresce a importância da educação financeira e da compreensão do sistema monetário contemporâneo nacional e mundial, imprescindíveis para uma inserção crítica e consciente no mundo atual. Diante desse cenário, impõem-se novos desafios às Ciências Humanas, incluindo a compreensão dos impactos das inovações tecnológicas nas relações de produção, trabalho e consumo (BNCC p.568).
\end{abstract}

Observa-se, a partir dessa consideração, a preocupação da normativa com a construção de sujeitos sociais capazes de refletir e interagir com o meio em que estão inseridos e nele desenvolver-se e estruturar-se de acordo com as mudanças 
econômicas e pertinentes ao mundo do trabalho e dos negócios de forma sustentável. No campo da Matemática, a Educação Financeira aparece já no Ensino Fundamental, abordando conceitos pertinentes à matemática financeira e oferecendo ferramentas aos estudantes como técnicas de cálculo, raciocínio lógico e possibilitando que esses conceitos possam ser imbricados com outras áreas do conhecimento, ampliando o repertório dos alunos e conferindo-lhes maior capacidade de detectar e resolver problemas e situações complexas em seu cotidiano.

\begin{abstract}
Outro aspecto a ser considerado nessa unidade temática é o estudo de conceitos básicos de economia e finanças, visando à educação financeira dos alunos. Assim, podem ser discutidos assuntos como taxas de juros, inflação, aplicações financeiras (rentabilidade e liquidez de um investimento) e impostos. Essa unidade temática favorece um estudo interdisciplinar envolvendo as dimensões culturais, sociais, políticas e psicológicas, além da econômica, sobre as questões do consumo, trabalho e dinheiro. É possível, por exemplo, desenvolver um projeto com a História, visando ao estudo do dinheiro e sua função na sociedade, da relação entre dinheiro e tempo, dos impostos em sociedades diversas, do consumo em diferentes momentos históricos, incluindo estratégias atuais de marketing. Essas questões, além de promover o desenvolvimento de competências pessoais e sociais dos alunos, podem se constituir em excelentes contextos para as aplicações dos conceitos da Matemática Financeira e também proporcionar contextos para ampliar e aprofundar esses conceitos (BNCC p.269).
\end{abstract}

Como finalidades do Ensino Médio na contemporaneidade, considerando as transformações econômicas, sociais e culturais, tanto no âmbito nacional como internacional, a BNCC aponta para a necessidade da formação geral do indivíduo para permitir o exercício da cidadania, a inserção no mundo do trabalho em constante mudanças em função do desenvolvimento tecnológico. A formação geral proposta pela BNCC inclui a educação integral dos estudantes com a construção de seu projeto de vida, proporcionando aprendizagens alinhadas às necessidades, possibilidades e interesses dos jovens, para que possam enfrentar os desafios do mundo do trabalho.

Para a implementação de seu próprio projeto de vida, o desenvolvimento de capacidades de abstração, reflexão, interpretação, proposição e ação são indispensáveis. E essas capacidades estão diretamente relacionadas aos conhecimentos de Educação Financeira, que propiciarão ao jovem assumir o protagonismo de sua vida profissional em um mundo cada vez mais complexo e imprevisível. O conhecimento de Educação Financeira torna-se um sólido alicerce para o equilíbrio financeiro no presente e perspectivas de bem-estar no futuro.

$\mathrm{Na}$ área de Matemática e suas tecnologias pode-se observar a presença, de forma transversal, de conteúdos relacionados à Educação Financeira. A proposta na área de Matemática para o Ensino Médio é consolidar, ampliar e aprofundar as aprendizagens desenvolvidas no Ensino Fundamental, de forma que os estudantes percebam a Matemática numa perspectiva aplicada à realidade, nos diferentes contextos em que vivem.

A aprendizagem dos conceitos matemáticos aplicados à realidade permitirá aos estudantes a atuação como protagonistas de seu projeto de vida, sendo capaz 
de identificar e resolver problemas em diversos contextos, com autonomia e consciência, fazendo uso dos recursos matemáticos. Essa aprendizagem é fundamental para que o letramento matemático e letramento financeiro sejam densos e eficientes, possibilitando o pleno exercício da cidadania e construção do projeto de vida.

Nas competências especificas de Matemática e suas tecnologias para o Ensino Médio verifica-se que todas se relacionam direta ou indiretamente aos conceitos e conhecimentos de Educação Financeira, temática que deverá ser inserida no currículo de forma transversal:

a) Utilizar estratégias, conceitos e procedimentos matemáticos para interpretar situações em diversos contextos, sejam atividades cotidianas, sejam fatos das Ciências da Natureza e Humanas, das questões socioeconômicas ou tecnológicas, divulgadas por diferentes meios, de modo a contribuir para uma formação geral;

b) Propor ou participar de ações para investigar desafios do mundo contemporâneo e tomar decisões éticas e socialmente responsáveis com base na análise de problemas sociais, como os voltados a situações de saúde, sustentabilidade, das implicações da tecnologia no mundo do trabalho, entre outros, mobilizando e articulando conceitos, procedimentos e linguagens próprios da Matemática;

c) Utilizar estratégias, conceitos, definições e procedimentos matemáticos para interpretar, construir modelos e resolver problemas em diversos contextos, analisando a plausibilidade dos resultados e a adequação das soluções propostas, de modo a construir argumentação consistente;

d) Compreender e utilizar, com flexibilidade e precisão, diferentes registros de representação matemáticos (algébrico, geométrico, estatístico, computacional etc.), na busca de solução e comunicação de resultados de problemas;

e) Investigar e estabelecer conjecturas a respeito de diferentes conceitos e propriedades matemáticas, empregando estratégias e recursos, como observação de padrões, experimentações e diferentes tecnologias, identificando a necessidade, ou não, de uma demonstração cada vez mais formal da validação das referidas conjecturas. (BNCC, p. 531).

Dentro do itinerário formativo de Matemática e suas tecnologias, encontrou-se apenas duas habilidades relacionadas à $3^{\text {a }}$ competência específica que se relacionam diretamente com a Educação Financeira.

EM13MAT304 - Resolver e elaborar problemas com funções exponenciais nos quais seja necessário compreender e interpretar a variação das grandezas envolvidas, em contextos como os de abalos sísmicos, $\mathrm{pH}$, radioatividade, Matemática Financeira, entre outros.

EM13MAT305 - Resolver e elaborar problemas com funções exponenciais nos quais seja necessário compreender e interpretar a variação das grandezas envolvidas, em contextos como os de abalos sísmicos, $\mathrm{pH}$, radioatividade, Matemática Financeira, entre outros.

Dentre os itinerários formativos previstos para o Ensino Médio, nas demais áreas do conhecimento, constata-se a indicação de temáticas indiretamente

Refas - ISSN 2359-182X v.8, n.3 Fevereiro de 2022


relacionadas à Educação Financeira nas competências específicas para cada uma das demais áreas do conhecimento, conforme indicado no Quadro 2.

Quadro 1 - Competências relacionadas à Educação Financeira

\begin{tabular}{|c|l|}
\hline Área & \multicolumn{1}{|c|}{ Competências Específicas } \\
\hline $\begin{array}{c}\text { Linguagens e suas } \\
\text { tecnologias }\end{array}$ & $\begin{array}{l}\text { Utilizar diferentes linguagens (artísticas, corporais e verbais) para exercer, com } \\
\text { autonomia e colaboração, protagonismo e autoria na vida pessoal e coletiva, de } \\
\text { forma crítica, criativa, ética e solidária, defendendo pontos de vista que } \\
\text { respeitem o outro e promovam os Direitos Humanos, a consciência } \\
\text { socioambiental o o consumo responsável, em âmbito local, regional e global. } \\
\text { (BNCC, p. 490) }\end{array}$ \\
\hline $\begin{array}{c}\text { Ciências da natureza e e } \\
\text { suas tecnologias }\end{array}$ & $\begin{array}{l}\text { Analisar fenômenos naturais e processos tecnológicos, com base nas interações e } \\
\text { relações entre matéria e energia, para propor ações individuais e coletivas que } \\
\text { aprfeiçoem processos produtivos, minimizem impactos socioambientais e } \\
\text { melhorem as condições de vida em âmbito local, regional e global. (BNCC. p. } \\
\text { 553) }\end{array}$ \\
\hline $\begin{array}{c}\text { Ciências humanas e } \\
\text { sociais aplicadas }\end{array}$ & $\begin{array}{l}\text { Analisar e avaliar criticamente as relações de diferentes grupos, povos e } \\
\text { sociedades com a natureza (produção, distribuição e consumo) e seus impactos } \\
\text { econômicos e socioambientais com vistas à proposição de alternativas que } \\
\text { respeitem e promovam a consciência, a ética socioambiental e o consumo } \\
\text { responsável em âmbito local, regional, nacional e global. } \\
\text { Analisar as relações de produção, capital e trabalho em diferentes territórios, } \\
\text { contextos e culturas, discutindo o papel dessas relações na construção, } \\
\text { consolidação e transformação das sociedades. } \\
\text { Participar do debate público de forma crítica, respeitando diferentes posiçães e } \\
\text { fazendo escolhas alinhadas ao exercício da cidadania e ao seu projeto de vida, } \\
\text { com liberdade, autonomia, consciência crítica e responsabilidade. } \\
\text { (BNCC, p. 570) }\end{array}$ \\
\hline
\end{tabular}

Fonte: Elaborado pelos autores

O Quadro 2 evidencia que não está clara a conexão entre Educação Financeira e os conteúdos das áreas de conhecimento propostos na BNCC. Percebe-se a lacuna com relação a como o professor poderá inserir o tema Educação Financeira no currículo de cada uma das disciplinas que compõem o currículo escolar, especialmente considerando que não grande parte dos educadores não tiveram acesso a uma formação específica na área de Educação Financeira. O desafio que se apresenta ao professor é como associar sua disciplina a conhecimentos com os quais não está preparado e, muitas vezes, nem familiarizado. 


\section{CONSIDERAÇÕES FINAIS}

O que se buscou na construção desse estudo foi compreender de que maneira a BNCC sugere a implementação da Educação Financeira nos currículos das instituições de ensino e quais as suas proposições no direcionamento das ações das escolas. O tema é tratado como assunto transversal, que pode ser discutido em diversas áreas do conhecimento, de forma a proporcionar aos estudantes a capacidade de desenvolver seu senso crítico e sua capacidade de ser sujeito em um mundo que passa por transformações tecnológicas cada vez mais disruptivas e com intervalos de tempo cada vez menores.

Ao propor a forma como a EF deve ser tratada no estudo da Matemática, os conteúdos são direcionados para o desenvolvimento das habilidades e competências voltadas para o cálculo, o raciocínio lógico e o pensamento pragmático, que atribuam aos estudantes o poder de reflexão contínua e sistematizada. E o que se observa, consequentemente, é um foco maior da normativa na área da matemática do que nas outras áreas de estudos, isso pode ser percebido pelo aprofundamento que se tem sobre EF dentro do campo da matemática, bem como as proposições e tópicos abordados. Não é um problema em si, naturalmente, que se coloque maior atenção de um tema dentro de uma área do conhecimento específica, no entanto, é preciso que se atente para o fato de que se a proposta da normativa é distribuir os conteúdos em diversas áreas (a EF pelo documento é uma competência transversal) para que eles façam sentido de forma universal e agregadora, conferindo aos estudantes um conhecimento que se imbrica e se inter-relaciona também com as suas próprias vidas, talvez fosse mais potente ampliar a incidência e o estudo de EF em outras áreas do conhecimento, como a própria BNCC se propõe a fazer e, no ponto de vista desse estudo, não fica claro para o leitor da norma como a EF possa ser implementada como tema transversal, dentre as competências previstas na normativa.

O estudo não se fecha em si mesmo, deixando em aberto novos questionamentos a serem investigados, tais como: como a norma tratará a formação dos profissionais de educação, os docentes, que concretamente serão os responsáveis, na linha de frente, por viabilizar estes conteúdos para os alunos de diferentes contextos socioeconômicos e variadas relações com o dinheiro? A BNCC trata e considera as regionalidades, em que pesem as proporções do Estado Brasileiro, na estruturação das suas proposições? De que formas?

Ao finalizar o presente artigo sugere-se que sejam abertas novas e outras perspectivas de estudos e aprofundamentos acerca das iniciativas de Educação Financeira em curso no país para analisar e identificar possibilidades e alternativas para a inclusão do assunto como tema transversal na educação básica. 


\section{REFERÊNCIAS}

\subsection{Referências legais}

BRASIL. Lei 9.394, de 20 de dezembro de 1996. Estabelece as diretrizes e bases da educação nacional. Diário Oficial da União, Brasília, 23 de dezembro de 1996. Disponível em:

<http://www.planalto.gov.br/ccivil_03/leis/L9394.htm>. Acesso em: 15 jul.2021.

BRASIL. Ministério da Educação; Secretaria de Educação Básica; Secretaria de Educação Continuada, Alfabetização, Diversidade e Inclusão; Secretaria de Educação Profissional e Tecnológica. Conselho Nacional de Educação; Câmara de Educação Básica. Diretrizes Curriculares Nacionais da Educação Básica. Brasília: MEC; SEB; DICEI, 2013. Disponível em: <http://portal.mec.gov.br/index.php?option=com_docman\&view=download\&alias $=\quad 13448$ diretrizes-curiculares-nacionais-2013-pdf\&Itemid=30192>. Acesso em: 16 jul. 2021.

BRASIL. Decreto N $\mathbf{5 . 6 8 5}$ de 25 de janeiro de 2006. Disponível em <https://www2.camara.leg.br/legin/fed/decret/2006/decreto-5685-25-janeiro-2006-540598publicacaooriginal-41102-pe.html> Acesso em 27.jul.2021.

BRASIL. Deliberação $\mathbf{N}^{\mathbf{3}} \mathbf{3}$ de 31 de maio de 2007. Disponível em <https://www.vidaedinheiro.gov.br/wp-content/uploads/2017/04/05-08-2014-COREMEC-

Deliberacao3.pdf> Acesso em 27.jul.2021.

BRASIL. Decreto 7397 de 22/12/20210 que institui a ENEF. Disponível em <https://www.planalto.gov.br/ccivil_03/_ato2007-2010/2010/decreto/d7397.htm> Acesso em 28.jul.2021.

BRASIL. Decreto 10393 de 9 de junho de 2020, institui a nova ENEF.

Disponível em <http://www.planalto.gov.br/ccivil_03/_Ato20192022/2020/Decreto/D10393.htm\#art10> Acesso em 28.jul.2021.

BRASIL. Lei 12.796 de 4 De Abril De 2013. Disponível em <http://www.planalto.gov.br/ccivil_03/_ato2011-2014/2013/lei/112796.htm> Acesso em 30.jul.2021.

BRASIL. Lei $\mathbf{1 3 . 4 1 5}$ de 16 de fevereiro de 2017. Disponível em <http://www.planalto.gov.br/ccivil_03/_ato2015-2018/2017/lei/113415.htm >Acesso em: 30.jul.2021.

\subsection{Referências bibliográficas}

BRITTO, Reginaldo R. Educação Financeira: uma pesquisa documental crítica. Universidade Federal de Juiz de Fora - Instituto de Ciências Exatas - Pós-graduação em Educação Matemática - Mestrado profissional em Educação Matemática. Juiz de Fora-MG, 2012.

FORTE, C. (org.). Estratégia Nacional de Educação Financeira (ENEF): em busca de um Brasil melhor. $1^{\text {a }}$ ed. São Paulo: Riemma Editora, 2020

LÜDKE, M. Pesquisa em educação: abordagens qualitativas / Menga Lüdke, Marli E. D. A. André. $2^{\mathrm{a}}$ ed - [Reimpr.], Rio de Janeiro: E.P.U., 2020. 
MACEDO, E. F. Parâmetros curriculares nacionais: a falácia de seus temas transversais. Artigo disponível no livro: Currículo: Políticas e Práticas/ Antonio Flavio Barbosa Moreira (org.) - Campinas: Papirus, 1999. - (Coleção Magistério: Formação e Trabalho Pedagógico)

OCDE. Centro OCDE/CVM de Educação e alfabetização financeira para América Latina e Caribe. Recomendações sobre os princípios e as boas práticas de educação e conscientização financeira. 2005. Disponível em < https://www.oecd.org/daf/fin/financialeducation $/ \% 5$ bPT $\% 5$ d $\% 20$ Recomendação\%20Princ\%C3\%ADpios $\% 20$ de $\% 20$ Educação\%20F inanceira\%202005\%20.pdf> Acesso em 26.jul.2021.

PERRENOUD, P. et al. As competências para ensinar no século XXI: a formação dos professores e o desafio da avaliação. Tradução> Claudia Schiliing e Fatima Murad. Porto Alegre: Artmed Editora, 2002. 176p.

PUCCI, R. H. P., SOUZA, T. A. Formação continuada de professores da educação básica no contexto de implementação da BNCC - In: BNCC em cenários atuais [livro eletrônico]: currículo, ensino e a formação docente / organização Micheli Bordoli Amestoy, Ivanio Folmer, Gabriella Eldereti Machado. 1ed. Santa Maria, RS. Arco Editores: 2021. (p.11-26).

RIFIKIN, Jeremy. O fim dos empregos: o declínio inevitável dos níveis de empregos e a redução da força global de trabalho. São Paulo: Makron Books, 1995.

SACRISTÁN, J. G. Educar e conviver na cultura global: as exigências da cidadania. Tradução Ernani Rosa. $1^{a}$ ed. - Porto Alegre, RJ: Artmed Editora, 2002.

SACRISTAN, J. G. Saberes e Incertezas Sobre o Currículo 1.ed. Porto Alegre: Penso 2013. 544 p.

\subsection{Notícias e textos em veículos de imprensa}

BC. BC lança expansão nacional do programa Aprender Valor. Disponível em: < https://www.bcb.gov.br/detalhenoticia/553/noticia > Acesso em 28.jul.2021.

LEWGOY, J. Educação financeira nas escolas fica para trás em meio à democratização de investimentos. Disponível em: <https://valorinveste.globo.com/educacaofinanceira/noticia/2021/06/22/educacao-financeira-nas-escolas-fica-para-tras-em-meio-ademocratizacao-de-investimentos.ghtml> Acesso em 28/07/21

MEC. Assessoria de comunicação social. Conferências sobre educação financeira acontecerão em maio. Disponível em:< http://portal.mec.gov.br/component/tags/tag/35987educacao-financeira> Acesso em 28.jul.2021. 